\title{
Influência da concentração de proteína, da força iónica e o tipo de hidrato de carbono na formação de complexos tanino-proteína
}

\section{Influence of protein concentration, ionic strength and type of carbon hydrate in training complex tannin-protein}

\author{
Amanda Priscila Silva Nascimento ${ }^{1}$, Ana Luisa Pinto ${ }^{1}$, Maria Elita Martins Duarte ${ }^{2}$, Francinalva Cordeiro de Sousa ${ }^{3}$, \\ Alfredina dos Santos Araújo
}

\begin{abstract}
Resumo: Os taninos são compostos naturais que têm a propriedade de complexarem com as proteínas formando agregados insolúveis em solução. A interação destes compostos com as proteínas salivares leva à sensação de adstringência de alguns frutos (especialmente se pouco maduros) e bebidas como o vinho tinto e o chá. No presente estudo pretende-se verificar de que forma a concentração de protéina e tanino, as suas estruturas, hidratos de carbono e ainda a força iónica, podem influênciar a formação de complexos tanino-proteina. Verificou-se que menores concentrações de proteína no meio vão provocar um aumento da adstringência. A estrutura da proteína também irá influência a formação de complexos tanino-proteína, o aumento da força iónica irá provocar uma diminuição da formação de complexos tanino-proteína, hidratos de carbono com uma estrutura não capsolante em elevadas concentrações irão provocar uma aumento da adstringência, ao contrário de hidratos de carbono com uma estrutura capsolante.
\end{abstract}

Palavras-chave: Tanino, Proteína, Hidrato de carbono, Força iónica.

\begin{abstract}
The tannins are natural compounds which have the property of complexing with proteins form insoluble aggregates in solution. The interaction of these compounds with salivary proteins leads to the sensation of astringency of some fruits (especially if unripe) and drinks such as red wine and tea. The present study intends to check how the concentration of protein and tannin, their structures, carbohydrate and ionic strength also may influence the formation of tannin-protein complexes. It was found that lower protein concentrations in the medium will cause an increase in astringency. The protein structure will also influence the formation of tannin-protein complexes. Increasing the ionic strength will cause a reduction in the formation of tannin-protein complexes. Carbohydrates with a structure not capsolante in high concentrations will cause an increase in astringency, unlike carbohydrates with a capsolante structure.
\end{abstract}

Key words: Tannin, Protein, Carbohydrate, ionic strength.

\footnotetext{
*Autor para correspondência

Recebido para publicação em 22/01/2016; aprovado em 22/03/2016

${ }^{1}$ Aluna do Curso de Engenharia de Alimentos, Unidade Acadêmica de Engenharia de Alimentos, UFCG, Campina Grande, PB, E-mail: amandapriscil@yahoo.com.br

${ }^{2}$ Aluna do Mestrado de Biotecnologia e Qualidade Alimentar, Escola de Ciências da Vida e do Ambiente, Uiversidade Trás-os-Montes e Alto Douro, UTAD,

E-mail: analuisapinto91@ gmail.com

${ }^{3}$ Engenheira Agrícola, Professora. Doutora, Unidade Acadêmica de Engenharia de Alimentos, UFCG, Campina Grande, PB, E-mail: elita.duarte@ufcg.edu.br

${ }^{4}$ Doutoranda em Engenharia Agrícola, Unidade Acadêmica de Engenharia Agrícola, UFCG, Campina Grande, PB, E-mail: francis_nalva@yahoo.com.br
} 


\section{INTRODUÇÃO}

Em certos alimentos a adstringência destacar-se como uma característica sensorial importante, mais que a cor ou mesmo o aroma, caracterizada por uma secura da superfície oral e uma sensação de rugosidade em torna dos músculos da boca (BACON; RHODES, 1998). Esta sensação resulta de interações que ocorrem entre polifenóis (mais concretamente taninos) presentes nos alimentos, bebidas e as proteínas salivares, originando a formação de agregados proteína-tanino, que acabam por precipitar, causando a sensação de secura e constrição (BAJEC; PICKERING, 2008).

Os taninos são por definição compostos polifenólicos solúveis em água, com peso molecular variável, com a propriedade de complexarem com as proteínas ou polissacarídeos, formando agregados em solução. Estes compostos podem ser classificados em: polifenóis condensados ou hidrolisáveis (HASLAM, 1989).

A formação de agregados insolúveis proteína-tanino envolve ligações do tipo cruzadas entre as cadeias peptídicas da proteína e os taninos. Estas interações envolvem ligações por pontes de hidrogénio (ocorrem entre os grupos hidroxilo dos polifenóis e os grupos carbonilo das proteínas.) e interações hidrofóbicas (que se estabelecem entre o núcleo aromático do polifenol e os grupos ou aminoácidos hidrofóbicos da cadeia peptídica, como por exemplo a prolina) (JOBSTL et al., 2006)

As interações entre os taninos e as proteínas podem ser afetadas por vários fatores, que vão provocar alterações na adstringência do alimentos. Entre estes fatores, destacam-se a concentração de proteínas e taninos, as suas estruturas, a presença de outras moléculas (por exemplo hidratos de carbono), e ainda fatores experimentais, como $\mathrm{pH}$, a força iónica, a temperatura e a concentração em etanol (HORNE et al., 2002; EREL-UNAL; SUKHISHVILI, 2008; OBREQUESLIER et al., 2010).

Há alimentos cosiderados potencialmente adstringentes como chás, vinhos tintos, cervejas, que têm associados uma cultura social, que contribui para o consumidor apreciar estes alimentos mesmo sendo adstringentes. Nos cachos de uvas, os taninos estão presentes na película, grainhas e engaço. A concentração existente no vinho depende da variedde da uva, dos métodos de vinificação usados e pode ainda ser de origem exógena. (HASLAM, 1989). Ao nível da análise sensorial tendem a classificar o vinho adstringente usando descritores como "com carácter" e "bom final de boca", que não são propriamente depreciativo (LESSCHAEVE; NOBLE, 2005).

No presente estudo pretende-se verificar de que forma a concentração de protéina e tanino, as suas estruturas, a presença de outras moléculas (por exemplo: hidratos de carbono) e ainda fatores experimentais como a força iónica podem influênciar a formação de complexos tanino-proteina ou seja a adstringência.

\section{MATERIAL E MÉTODOS}

Para o presente trabalho procedeu-se à preparação das seguintes soluções de trabalho:

1. Taninos - Dissolveu-se os taninos na solução tampão de acetato $(0,1 \mathrm{M}, \mathrm{pH} 5,0)$ /etanol a $12 \%(\mathrm{v} / \mathrm{v})$ para obter uma concentração $0,2 \mathrm{~g} / \mathrm{L}$.
2. Albumina de ovo - Preparou-se uma solução de albumina do ovo $0,30 \mathrm{mM}$ na solução tampão de acetato $(0,1 \mathrm{M}, \mathrm{pH} 5,0)$ /etanol a $12 \%(\mathrm{v} / \mathrm{v})$.

3. Gelatina - Preparou-se uma solução de gelatina 0,30 $\mathrm{mM}$ na solução tampão acetato $(0,1 \mathrm{M}, \mathrm{pH} 5,0)$ /etanol a $12 \%(\mathrm{v} / \mathrm{v})$.

4. Hidratos de carbono - Preparou-se as seguintes soluções de hidratos de carbono na solução tampão de acetato $(0,1 \mathrm{M}, \mathrm{pH} 5,0)$ /etanol a $12 \%(\mathrm{v} / \mathrm{v})$ : $100 \mathrm{~g} / \mathrm{L}$ glucose, $100 \mathrm{~g} / \mathrm{L}$ Goma-arábica; $100 \mathrm{~g} / \mathrm{L}$ Pectina.

5. Preparou-se uma solução de $\mathrm{NaCl}$ a $1 \mathrm{M}$ na solução tampão de acetato $(0,1 \mathrm{M}, \mathrm{pH} 5,0) /$ etanol a $12 \%(\mathrm{v} / \mathrm{v})$.

Influência da natureza e concentração de proteína na formação de agregados insolúveis com os taninos

Em 7 tubos de ensaio pipetou-se $5 \mathrm{ml}$ da solução de tanino a testar, acionando-se 0,1(A); 0,5 (B); 1 (C); 1,5(D); $2(\mathrm{E}) ; 3(\mathrm{~F}) ; 5(\mathrm{G}) \mathrm{ml}$ da solução de proteína a testar (gelatina ou albuvina de ovo), ajustando o volume final com a solução tampão de acetato $(0,1 \mathrm{M}, \mathrm{pH} 5,0) /$ etanol a $12 \%$ (v/v). Após mistura das soluções deixe permanecer 30 min à temperatura ambiente sem agitação. Após este período agite novamente a solução e leia a turbidez.

\section{Influência da Força iónica na formação de agregados insolúveis com os taninos}

Utilizando a razão tanino/proteína para o qual se obteve uma maior turbidez, adicione novamente em cinco tubos de ensaio $5 \mathrm{ml}$ da solução de tanino, 1, 2, 3, 4 e $5 \mathrm{ml}$ da solução de $\mathrm{NaCl} 1 \mathrm{M}$ e o volume x de proteína. Após mistura das soluções deixe permanecer $30 \mathrm{~min}$ à temperatura ambiente sem agitação. Após este período agite novamente a solução e leia a turbidez.

Influência da natureza e concentrção de hidratos de carbono na formaçao de agregados insolúveis com os taninos

Utilizando a razão tanino/proteína para o qual obteve uma maior turbidez, adicione novamente em cinco tubos de ensaio $5 \mathrm{ml}$ da solução de tanino, 1, 2, 3, 4 e $5 \mathrm{ml}$ da solução de hidrato de carbono e o volume $\mathrm{x}$ de proteína. Após mistura das soluções deixou-se permanecer $30 \mathrm{~min}$ à temperatura ambiente sem agitação. Após este período procedeu-se À agitação novamente da solução e leu-se a turbidez

\section{RESULTADOS E DISCUSSÃO}

Os resultados obtidos na influência da natureza e concentração de proteína na formação de agregados insolúveis com os taninos encontram-se na Tabela 1. Pela análise da tabela 1 verificamos que a presença de baixas concentrações de proteína os taninos propagam-se pela sue superfície numa única camada, fazendo diminuir o seu carácter hidrofílico. As proteínas "amontoam-se", e eventualmente precipitam, aumentando assim a turbidez da solução, pois os taninos ao ligar-se à proteína não vão permitir que esta estabeleça ligações com a água ficando um composto insolúvel, precipitando. Por outro lado, se a concentração de proteína for elevada os polifenóis expandemse à superfície. No entanto neste caso a quantidade de tanino não vai ser suficiente para rodear toda a proteína permitindo que esta estabeleça interacções com a água (demostrado na 
figura 1). Este facto vai permitir que ocorre uma menor formação dos complexos insolúveis taninos - proteínas pois a proteína vai estabelecer ligações com a água, permitindo uma diminuição da adstringência. Segundo (DE FREITAS et al.
(2003) a solubilização dos agregados tanino/albumina de bovino (BSA) formados aumenta com o aumento da concentração de proteína.

Tabela 1: Soluções de trabalho para a Albumina do ovo

\begin{tabular}{ccccccc}
\hline & $\begin{array}{c}\text { Solução } \\
\text { Tampão }(\mathbf{m l})\end{array}$ & $\begin{array}{c}\text { Solução proteína } \\
(\mathbf{m l})\end{array}$ & $\begin{array}{c}\text { Concentração } \\
\text { proteina (mM) }\end{array}$ & $\begin{array}{c}\text { Tanino/ } \\
\text { Proteína }\end{array}$ & $\begin{array}{c}\text { Turbidez } \\
\text { Albumina }\end{array}$ & $\begin{array}{c}\text { Turbidez } \\
\text { Gelatina }\end{array}$ \\
\hline $\mathbf{A}$ & 4,9 & 0,1 & $3,0 \times 10^{-3}$ & 33,33 & 305 & 235 \\
$\mathbf{B}$ & 4,5 & 0,5 & $1,5 \times 10^{-1}$ & 6,67 & 541 & 420 \\
$\mathbf{C}$ & 4,0 & 1,0 & $3 \times 10^{-2}$ & 3,33 & 510 & 205 \\
$\mathbf{D}$ & 3,5 & 1,5 & $4,5 \times 10^{-4}$ & 2,22 & 400 & 193 \\
E & 3,0 & 2,0 & $6 \times 10^{-2}$ & 1,67 & 317 & 119 \\
F & 2,0 & 3,0 & $9 \times 10^{-2}$ & 1,11 & 29 & 73 \\
G & 0 & 5,0 & $1,5 \times 10^{-2}$ & 6,67 & & 29 \\
\hline
\end{tabular}

Relativamente ao comportamento das duas proteinas em estudo (albumina e gelatina), em termos teóricos, o que deveria ter ocorrido era menores valores de turbidez para a albumina comparativamente com a gelatina, devido ás estruturas que ambas as proteínas apresentam. Isto é, a gelatina é uma proteína linear, rica em aminoácidos hidrofóbicos, o que the confere maior afinidade para os taninos. Por outro lado, a albumina apresenta uma estrutura globular, logo possui menor afinidade para os taninos, e consequentemente para a formação de complexos insolúveis taninos - proteínas.

Figura 1: Interação Tanino Proteína. No primeiro caso, o que ocorre quando o tanino está em contacto com uma baixa concentração de proteína, e no segundo o que ocorre quando tanino está em contacto com uma elevada concentração de proteína.

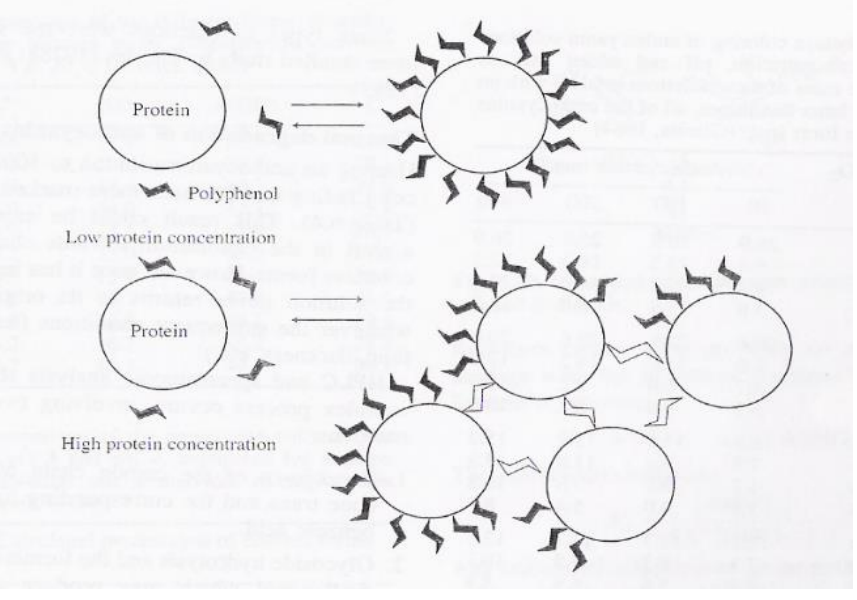

Os resultados referentes à influência da força iónica na formação de agregados insolúveis com os taninos encontram-se na tabela 2 .
Tabela 2: Soluções de trabalho para diferentes forças iónicas

\begin{tabular}{lccccc}
\hline & A & B & C & D & E \\
\hline Solução Tanino (ml) & 5,0 & 5,0 & 5,0 & 5,0 & 5,0 \\
Solução NaCl (ml) & 1,0 & 2,0 & 3,0 & 4,0 & 5,0 \\
Solução Tampão (ml) & 4,5 & 4,5 & 4,5 & 4,5 & 4,5 \\
Solução proteína (ml) & 0,5 & 0,5 & 0,5 & 0,5 & 0,5 \\
Força iónica & 0,09 & 0,17 & 0,23 & 0,29 & 0,33 \\
Turbidez albumina & 462 & 352 & 257 & 197 & 200 \\
Turbidez gelatina & 310 & 191 & 110 & 237 & 112 \\
\hline
\end{tabular}

Em vários resultados descritos, a aumento da força iónica induz um aumento da agregação de complexos taninoproteína e um aumento da precipitação (CANON et al., 2013). No entanto, parecem ocorrer resultados contraditórios Rawel et al. (2005) observaram uma diminuição da afinidade com aumento da força iónica. Pela análise da tabela 02 observamos que para valores elevados de $\mathrm{NaCl}$ (força iónica) ocorreu uma diminuição dos valores de turbidez, quer quando foi utilizado a albumina, quer quando foi utilizado a gelatina (DE FREITAS et al., 2003).

Na Tabela 3, encontram-se os valores da influência da natureza e concentrção de hidratos de carbono na formaçao de agregados insolúveis com os taninos.

Tabela 3: Resultados obtidos da determinação das antocianinas, fenóis totais e atividade antioxidante.

\begin{tabular}{|c|c|c|c|c|c|}
\hline & $\mathbf{A}$ & $\mathbf{B}$ & $\mathbf{C}$ & D & $\mathbf{E}$ \\
\hline Solução Tanino (ml) & 5,0 & 5,0 & 5,0 & 5,0 & 5,0 \\
\hline Solução Tampão (ml) & 4,5 & 4,5 & 4,5 & 4,5 & 4,5 \\
\hline Solução proteína $(\mathrm{ml})$ & 0,5 & 0,5 & 0,5 & 0,5 & 0,5 \\
\hline $\begin{array}{l}\text { Concentração } \\
\text { Glucose (g/l) }\end{array}$ & 9,1 & 16,7 & 23,7 & 28,6 & 33,3 \\
\hline $\begin{array}{l}\text { Concentração goma- } \\
\text { arábica }(\mathrm{g} / \mathrm{l})\end{array}$ & 0,90 & 1,66 & 2,30 & 2,86 & 3,33 \\
\hline $\begin{array}{l}\text { Concentração Pectina } \\
(\mathrm{g} / \mathrm{l})\end{array}$ & 0,90 & 1,66 & 2,30 & 2,86 & 3,33 \\
\hline Turbidez albumina & 473 & 449 & 399 & 335 & 242 \\
\hline Turbidez gelatina & 326 & 297 & 230 & 80 & 74 \\
\hline
\end{tabular}


Um dos factores que influencia a interacção entre proteínas e taninos é a presença de polissacarídeos em solução. No caso da Glucose esta vai ter um comportamento não capsolante, ao contrário dos outros dois hidratos de carbono estudados neste trabalho prática. Neste caso vai ocorrer a formação de um complexo terciário proteína/tanino/hidrato de carbono que, devido ao carácter hidrofílico dos hidratos de carbono, provoca uma maior solubilidade em solução aquosa. Ou seja, os hidratos de carbono deixam os taninos rodearem a proteína e só por último é que os hidratos de carbono vão rodear o complexo tanino/proteína. Quando a concentração de hidrato de carbono é suficiente vai rodear por completo a proteína e como os hidratos de carbono são solúveis em água este complexo não vai precipitar, diminuindo assim a turbidez da solução e consequentemente uma diminuição da adstringência. Pela análise da tabela 03 é de referir que a concentração de glucose vai aumentando ao longo do trabalho, logo espera-se que quando as concentração de hidrato de carbono são baixas para rodear todo complexo proteína/tanino, a turbidez seja alta, pois este complexo não vai ter a capacidade de o solubilizar. E este facto não se verificou, pois a turbidez desde logo do início vai diminuir (LUCK et al., 1994).

O comportamento da goma-arábica e da pectina como hidrato de carbono vai ser semelhante, pois são portadores de um comportamento "capsolante", o que vai ocorrer é uma competição entre o hidrato de carbono e a proteína para se ligar ao tanino, no entanto o hidrato de carbono com esta propriedade "capsolante", vai escolher preferencialmente o tanino, deixando a proteína livre no meio, permitindo que esta solubilize. O complexo tanino/proteína irá também solubilizar, devido ao facto do hidrato de carbono se ligar à superfície do tanino permitindo que se solubilize (HASLAM, 1989; LUCK et al., 1994).

Figura 2: Interação tanino/proteína/goma-arábica ou pectina

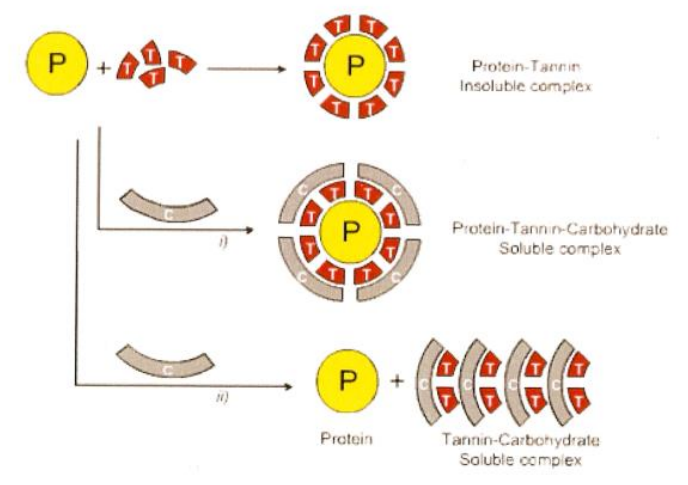

\section{CONCLUSÕES}

Quando estudado a influência da concentração de proteína mantendo constante a concentração de tanino, conclui-se que quanto menor a concentração de proteína, maior vai ser a interação entre os taninos e as proteínas, logo vai ocorrer uma maior precipitação dos mesmo e consequentemente maior turbidez e adstringência.

Relativamente ao efeito da força iónica observamos que, quando aumentamos a concentração de $\mathrm{NaCl}$, há um aumento da força iónica, o que vai favorecer a diminuição dos valores da turbidez e consequentemente a diminuição da adstringência.

Quanto ao estudo realizado para o efeito de três hidratos de carbono diferentes (glucose, goma arábica e pectina), concluímos que, no caso da glucose, que não possuí estrutura capsolante, ao aumentar a concentração desta, vai favorecer o aumento da turbidez da solução. No caso da goma-arábica e da pectina, que possuem estrutura capsolante, não há precipitação, a proteína vai estar solubilizada, logo ocorre a diminuição da turbidez.

Em modo de conclusão podemos afirma que a concentração de proteína assim como a estrutura que possui vão influência a adstringência no alimento. Menores concentrações no meio vão provocar um aumento da adstringência. No entanto, a presença de hidratos de carbono e a sua estrutura também irá ter influência. Hidratos de carbono com uma estrutura não capsolante (Glucose) em elevadas concentrações irão provocar uma aumento da adstringência, ao contrário de hidratos de carbono com uma estrutura capsolante (Pectina e Goma arábica).

\section{REFERÊNCIAS}

BACON, J. R.; RHODES, M. J. C. Development of a Competition Assay for the Evaluation of the Binding of Human Parotid Salivary Proteins to Dietary Complex Phenols and Tannins Using a Peroxidase-Labeled Tannin. Journal of Agricultural and Food Chemistry, 46, 5083-5088, 1998.

BAJEC, M. R \& PICKERING, G. J. Astringency: mechanisms and perception. Crit Rev Food Sci Nutr, 48, 858875, 2008.

CANNON, F; PATE, F; CHEYNIER, V; SARNIMANCHADO, P; GIULIANI, A; PEREZ, J; et al. Aggregation of the salivary proline-rich protein IB5 in the presence of the tannin EgCG. Langmuir, 29, 1926-1937, 2013.

DE FREITAS, V; CARVALHO, E \& MATEUS, N. Study of carbohydrate influence on protein-tannin aggregation by nephelometry. Food Chemistry, 81, 503-509, 2003.

EREL-UNAL, I \& SUKHISHVILI S.A. Hydrogen-bonded multilayers of a neutral polymer and a polyphenol. Macromolecules, 41, 3962-3970, 2008.

HORNE, J: HAYES, J. \& LAWLESS, H. T. Turbidity as a measure of salivary protein reactions with astringent substances. Chem Senses, 27, 653-659, 2002.

JOBSTIL, E; HOWSE, J. R; FAIRCLOUGH J.P \& WILLIAMSON, M. P. Noncovalent cross-linking of casein by epigallocatechin gallate characterized by single molecule force microscopy. J Agric Food Chem, 54, 4077-4081, 2006.

LESSCHAEVE, I. \& NOBLE, A.C. Polyphenols: factors influencing their sensory properties and their effects on food and beverage preferences. The American Journal of Clinical Nutrition, 81, 330S-335S, 2005.

LUCK, G; LIAO, H; MURRAY, N.J; GRIMMER, H. R; WARMINSKI, E.E; WILLIAMNOS, M.P; et al. 
Polyphenols, astringency and proline-rich proteins. Phytochemistry, 37, 357-371, 1994.

OBREQUE-SELIER, E; PENA-NEIRA, A \& LOPEZSOLIS, R. Enhancement of both salivary protein-enological tannin interactions and astringency perception by ethanol. J Agric Food Chem, 58, 3729-3735, 2010.

RAWEL, H. M; MEIDTHER, K \& KROLL, J. Binding of selected phenolic compounds to proteins. J Agric Food Chem, 53, 4228-4235, 2005. 